\title{
Competences in Context: Students' Expectations and Reflections as Guided by the Mobile Application Reflect. UP
}

\author{
Alexander Knoth $^{1}$ (D) Alexander Kiy ${ }^{1}$ (D) Ina Müller ${ }^{1}$ (D) $\cdot$ Mathias Klein ${ }^{1,2}$ (D)
}

Published online: 8 May 2019

(C) The Author(s) 2019

\begin{abstract}
Mobile applications are suitable as a structural possibility for students beginning their studies. Using the app Reflect.UP, students are encouraged to reflect on the organization, contents, and objectives of their studies. This article focuses on how students can acquire the academic ability to consider their own actions, which is an intrinsic component of academic professionalization. The work examines how a competency framework is derived through study regulations and module descriptions, and how subsequent questions for students' reflection are systematically created using this framework. Next, the hybrid mobile application Reflect.UP and its underlying software components are introduced, stimulating students' reflections on study content and objectives. The data gathered through the practical use of Reflect.UP is evaluated, and then the ensuing conclusions drawn from students' problems and learning processes for organizing the course of studies are explored. In addition, this paper reflects on the strengths and weaknesses of a mobile application as a sociological and technological compound for structural support of the introductory phase of education.
\end{abstract}

Keywords Introductory phase $\cdot$ Hybrid mobile application · Reflection ·

Professionalization · Competency framework

Alexander Kiy

alexander.kiy@uni-potsdam.de

Alexander Knoth

alexander.knoth@uni-potsdam.de

Ina Müller

ina.mueller@uni-potsdam.de

Mathias Klein

mathias.klein@uni-potsdam.de

1 Institute of Computer Science, Chair for Complex Multimedia Architectures, University of Potsdam, August-Bebel-Strasse 89, Potsdam, Germany

2 Faculty of Economics and Social Sciences, Coordinator for E-Learning and Introductory Phase, University of Potsdam, August-Bebel-Str. 89, Potsdam, Germany 


\section{Different Ways of Guiding Through the Introductory Phase of Study}

The first two semesters of commencing one's education are deemed to be crucial for studying successfully. Brodersen et al. describe the beginning of studies as "a symbolic induction into university in terms of a transition into a student (...) (see Turner 2005), accompanied by new freedoms of self-organization and determination, but also new requirements for self-discipline and self-government (see Foucault 1993; Lemke 2000)" (Brodersen et al. 2014). Thus, students are confronted with completely new challenges and overcoming them is interpreted as an indicator of their individual skills.

Regardless of the actual desire of school graduates to pursue an academic education or, preferably, taking an industry job, universities are under constant pressure by the OECD to increase the number of students and graduates. As a result, universities are concerned with lowering dropout rates (Vossensteyn et al. 2015) while, at the same time, enhancing students' aptitude for studying and their level of satisfaction, as well as ensuring a consistently high level of learning (Heublein et al. 2012). To achieve these objectives, universities are engaging in exceedingly diverse actions, some of which address prospective students (e.g., by online self-assessments or study abroad programs) or provide ongoing support for those in their first year of studies, for instance, with tutorials, mentoring, or counseling resources. Many of these offers are sequentially structured and/or time-dependent. Another approach is to provide readily available self-learning materials (e.g., mock exams), which require a high degree of personal initiative, motivation, and self-discipline from students in order to achieve the desired results. The most significant reasons why students drop out are already identified. Of all students, $18 \%$ have to manage a lack of motivation, because they no longer identify with their initially chosen field of studies. Financial problems and an incompatibility with studies and career are an issue for $19 \%$ of students, and nearly every third (30\%) is not able to cope with academic and study requirements. Thus, many do not even manage to get through the introductory phase (Heublein et al. 2009).

As a result, within the "Teaching Quality Pact", funded by the Federal Ministry of Education and Research in Germany, 125 projects address to improve and support the introductory phase of study. In addition, the German organization Stifterverband launched the educational initiative "Innovative Introductory Phase". These programs can be understood as an attempt to respond to the high dropout rates of almost $42 \%$ of Bachelor's degree students (Heublein et al. 2012), while, at the same time, the number of students increases and the number of graduates remains constant (KMK 2014). The introductory phase itself is thus shifting its focus equally on students and those responsible for study programs. A few examples will be briefly outlined here. Only a very limited number of the projects are using mobile applications as an innovative learning technology. Most of them aim at supporting students within specific offers that require physical attendance during their first weeks at higher education institutions. The project "For Really Good Studies" 1 at the PhillippsUniversität Marburg helps students during the orientation weeks, to acquire structured selfassessments on specific courses of study and to provide feedback on practical aspects of studies and teaching. This helps students to check their suitability for the selected study program as well as the decisions itself they have made. However, this offer is not aimed to make the required (subject-specific) competencies continuously transparent during the

\footnotetext{
1 https://www.uni-marburg.de/de/universitaet/administration/verwaltung/stabsstellen/qpl (last retrieved $02 / 19 / 19)$.
} 
study process. The project "The Introductory Phase"2 at the Bergische Universität Wuppertal focuses particularly on interactions in small groups, workshops, and practical faceto-face discussion forums, but omitting any reference to concrete learning activities. Other approaches shift from physical attendance to mobile and e-learning based concepts, which can be identified, for instance, within the context of a project at the Freie Universität Berlin named "SUPPORT". ${ }^{3}$ Especially the subproject "LEON_Learning Environments Online" 4 attempts to launch mobile teaching and learning applications to provide assistance to students during the orientation week by, again, focusing primarily on digitalized self-assessments and information. Nevertheless, there are also mobile projects, which aim to promote social interaction among freshmen. For example, the "Meet2Learn" application supports students in forming socially inclusive learning groups at the beginning of their studies (Philipp et al. 2013). Other applications use a game based approach to provide orientation knowledge to students. The pervasive learning game "FreshUP" convey information about university sites and specific procedures for new students in a playful context (Zender et al. 2013). In addition, the wide range of university apps also includes mobile support, but often in a rather rudimentary form, for instance, by navigating around the campus or enabling access to relevant information (Kiy et al. 2015). Some examples are:

1. "My UoL" a mobile application developed by the University of Leicester which provides students access to the course catalog, individualized study plan, and communication opportunities. $^{5}$

2. The University of Waterloo makes a mobile version of their student portal available, where students can get information about "books to buy, clubs to join, places to eat, places to be". 6

3. The University of Essex developed an application to support the welcome week and to help students with a digital guidebook. ${ }^{7}$

4. Very similar to the previous ones is the "Welcome weekend and First 50 Days" mobile application from the Miami University, which provides students information about their schedule, basic readings, and campus events. ${ }^{8}$

However, none of the presented examples combines both, the advantages of a mobile application and the thematic focus on self-reflection opportunities. The mobile application Reflect.UP, which is presented here, targets students' ability to reflect on commencing their studies and comprises both aspects: on the one hand, the support is not bound by time but, rather, is continually available for the first two semesters, providing the students with the opportunity for self-motivated reflection and feedback. On the other hand, students are stimulated with targeted questions that are "pushed" to their mobile device to engage on a regular basis. This demonstrates specific structural support for users.

\footnotetext{
2 https://www.wiwi.uni-wuppertal.de/de/service-amp-downloads/faqs/einschreibung-und-studienbeginn/ welcome-week-und-orientierungsphase.html (last retrieved 02/19/19).

3 https://www.fu-berlin.de/sites/qualitaetspakt/ (last retrieved 02/19/19).

${ }^{4}$ https://www.fu-berlin.de/sites/qualitaetspakt/leon/index.html (last retrieved 02/19/19).

5 https://le.ac.uk/study/welcome/when-here/settling-in/myuol-app (last retrieved 02/19/19).

6 https://uwaterloo.ca/student-portal/ (last retrieved 02/19/19).

7 https://guidebook.com/mobile-guides/essex-welcome-week-app/ (last retrieved 02/19/19).

${ }^{8}$ https://guidebook.com/app/miamioh/guide/miamiorientation/ (last retrieved 02/19/19).
} 
Through these resources, important topics of the introductory phase, such as dealing with study requirements, necessary skills (e.g., in self-organization and academic working), and factual knowledge (Kossack et al. 2012) can be imparted to students throughout their studies. The mobile application begins with the coaction of expectations with which the students are confronted. This concerns the divergent requirements of the university organization and the disciplines, as well as what students expect from their studies and from themselves (ibid.). Both students and those responsible for study programs can learn from these situations in this manner.

First, the current implementation of the introductory phase at the University of Potsdam is presented. Next, the theoretical cornerstones relating to the knowledgeable actor (Giddens 1988) and the reflection process within Reflect.UP are outlined. The pilot implementation of Reflect.UP at the Faculty of Economics and Social Sciences is used to introduce the derived competency framework, before explaining the application's functionalities and architecture. Lastly, the design and organization of the reflective questions and the obtained empirical results are examined. This article concludes with a brief outlook on further development and implementation steps.

\section{Hit the Ground Running: Acquiring Competencies to be Ready for Studies}

Design and implementation of the introductory phase at the University of Potsdam presents a heterogeneous picture. For instance, the Faculty of Science relies on preparatory bridge courses, orientation tutorials, mentoring, and, particularly, the open STEM room. ${ }^{9}$ The core element for this faculty is to assist new students in helping themselves with the support of students from more advanced semesters. In contrast, the Faculty of Human Sciences focuses particularly on acquiring key competencies in the domain of "Communication, Presentation, and Mediation". ${ }^{10}$ For other faculties, the design and organization of optional information events at the commencement of studies is the sole responsibility of student representatives. For approximately two years, the Faculty of Economics and Social Sciences has offered the obligatory module "Basic Academic Skills," within the scope of a structured introductory phase, which breaks down into the sub-modules "Methods of Scholarly Working and Writing" and "Self-Reflection and Planning." The latter consists of introductory tutorials for freshmen from the business administration, economics, political science, management, and sociology departments. Skills in scholarly working and writing are conveyed over the course of the semester, whereas self-reflection and planning are conducted in a condensed form at the onset of studies and immediately before the lecture period.

\footnotetext{
9 https://www.uni-potsdam.de/mnfakul/studium/offenermint-raum.html (last retrieved 02/19/19).

${ }^{10}$ https://www.uni-potsdam.de/humfak/studium-lehre/studieneingangsphase.html (last retrieved 02/19/19).
} 


\subsection{Organizational Structure and Embedding of the "Introductory Phase"}

Trained students from advanced semesters conduct the obligatory modules of the Faculty of Economics and Social Sciences, which occurs in small groups (15 to 20 students). An atmosphere of trust provides a safe space to ask questions and receive individual attention. This institutionalized possibility does not exist after the tutorials end, i.e. after the first semester. After this time, the Reflect.UP mobile application engages. The competencies to be conveyed in the introductory phase are clearly defined in the module catalogues for all courses of studies.

The "planning your studies" block of the module focuses, among other things, on meeting other students, campus orientation, an overview of study and examination regulations, and study planning. The experience gained in the past 3 years has demonstrated that first semester students sometimes have a specific idea of whether they intend to spend a semester abroad, take part in internships, or study for a master's degree. However, short-term semester planning is often underestimated, which can result in problems. An inability to immediately navigate one's way in the morass of deadlines for certain courses-making them up, registering, and withdrawing from them—can lead at best to frustration and, at worst, to unnecessarily prolonged time spent at university. It is intended that the application will provide remedies for these issues as well.

The "self-reflection" block contains topics such as work-life balance, time management, as well as various feedback methods for coping with and avoiding stress, along with models to optimize individual time management. Furthermore, the first semester students are sensitized to how they perceive themselves and are perceived by others, and general rules for creating a lively feedback culture are presented and practiced. This app is intended to support their studies in the continuous application of the feedback rules in seminars and group work. Here, an interface for the application is defined as a supporting tool to improve the feedback culture. In short: students train their personal skills (Orth 1999) and are, thus, able to organize their studies in an independent and purposeful manner.

Since winter semester 2013/2014 until 2016/2017, overall 1408 freshmen have evaluated the contents of the sub-module by filling out a feedback form. Of those surveyed, $79 \%$ agreed somewhat or strongly that the content conveyed was helpful for them. $15.6 \%$ were undecided and only $5.4 \%$ tend to not agree with this or do not agree at all. Taking this data into account, it has been determined that a (mobile) support offer should be created to start once the freshmen are on their own after the introductory tutorials. The app enables continuous self-assessments on the students' part, as well as a regular control of one's own self-competencies throughout the semester. Reflecting on one's own strengths and weaknesses is to be understood as a process that accompanies one's studies and that needs to be continuously fostered. Neither a 60-min tutorial nor concluding seminar evaluations adequately fulfill this task. In addition, the individual learning processes can be documented, and situation-specific questions and problems for freshmen can be addressed in a timely manner. In this context, the app functions as a digital extension of the obligatory self-reflection and planning sub-module.

\subsection{Qualifying Students Through Knowledge and Academic Skills}

Our proposal to support those commencing their studies is based on a mobile application that 
- Addresses critical awareness and students' reflections on the university's organizational and disciplinary requirements through the questions posed.

- Trains students' reflection skills as a prerequisite to professional competency.

- Makes it possible to regularly gather data about how students begin their studies.

- Sets up a "hotline" as a direct feedback option between students and those responsible for courses of studies.

In order to provide students with the best possible support and to adjust the structures of the university according to their needs, it is important to gather information on how students find their bearings and what specific challenges they are confronted with, when beginning their studies. Therefore, the following qualitative and explorative research question is addressed. How can a mobile application help student freshmen to reflect continuously the required competencies of their studies? To answer this question a process consisting of three stages (preparation phase, technical implementation phase and introductory phase) is presented. Each of the phases is guided by a sub-question, which has to be answered:

1. Where can the required competencies for student freshman be found and how should, according to the required competencies, a feasible set of reflective questions look like? Therefore, first, the required competencies, which have to be reflected by the freshmen, must be collected, generalized, and visualized from the module units and descriptions for every courses of studies. As a result, the competencies are made transparent and processed in form of reflective questions.

2. How must a mobile application framework be designed, and which functionalities must be implemented to at best address the needs of the target groups? Therefore, a reflection methodology and an associated mobile application, which fosters and supports reflection processes, is developed, implemented and tested.

3. Which insights into student's first semester can extracted from the data and which conclusions for the arrangement of students and study structures can be drawn? Consequently, the collected data (answers of reflective questions; commentaries, free feedback etc.) are interpreted and processed to those responsible for study programs, study development, and quality assurance procedures. This helps the institution to get a better understanding of their freshmen, their requirements, and needs. At best, these insights can help to modify the organizational structures and study programs, to better adjust the expected and required competencies of the freshmen.

Furthermore, there exists an opportunity for applying the whole approach to other higher education institutions by the use of more generalizable competencies regardless of the specific institution. The following Fig. 1 summarizes the cyclic research process, which is conducted for every new winter semester freshmen, consisting of the qualitative analysis of the module units, the implementation of the mobile application and the finally interpretation and processing of the derived results. 


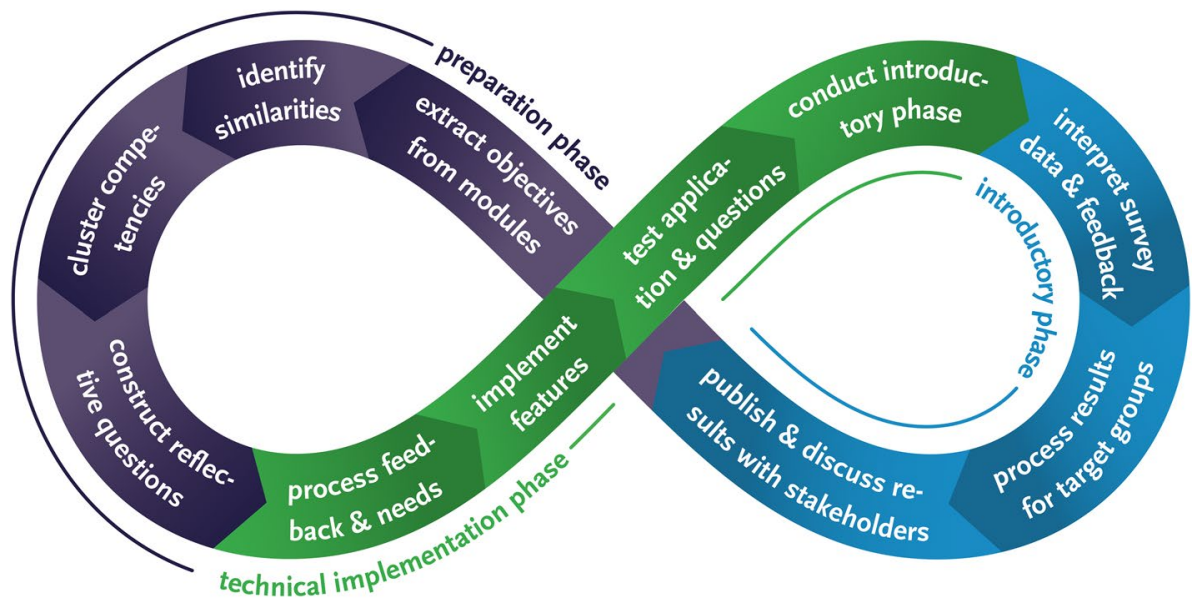

Fig. 1 Research process starting with the extraction of the objectives from the module units and concluding with the publication and discussion of the derived results with stakeholders

\section{Theoretical Cornerstones: Mobile Reflection}

\subsection{The Mobile Situated Knowledgeable Actor}

The concept of (mobile) situated learning (Giddens 1979; Bourdieu 1977; Rensing and Tittel 2013) offers a suitable anchor point for our proposal. It is considered, how actors make sense of specific situations and negotiate meaning within the situational context. From this perspective, the focus is on individual learners, who act in (operational) situations. This means that learning cannot be understood dissociated from processing everyday situations and their respective context. Situations can, thus, act, on the one hand, as a stimulus for individual learning and, on the other hand, as a source of knowledge to learn to what extent individuals grapple with certain topics when beginning their studies. Both students and the university itself are interested in studies commencing, progressing, and completing smoothly. Yet, how can these stages be best ensured structurally, and, at the same time, how can the experiences of actors, operating within university structures, be used to positively modify these organizational structures?

The idea of enabling the "practical awareness" of students is based on Giddens's (1988) actor concept, which rejects the contrary juxtaposition of structures and actions in favor of a dualistic and dynamically situated understanding. Structures flow directly into actors' actions, though actors' actions "create" structures. The core of this idea is the "knowledgeable" actor-a person who acts in a proactive way, and self-reflectively, thus embodying a competent member of society (Giddens 1988).

The heart of the application presented here is the development of an active and reflective actor, who finds his or her bearings in the university structures, depends on the situation, processes the structural requirements addressed to them and contributes to stabilizing or changing the organizational structures through their concrete conduct. It is attempted to positively influence this (processing) action by encouraging students to regularly reflect individually; feeding back the results of the reflection at any time makes this possible. Thus, individual knowledge becomes the prerequisite and object of reflection and makes successful action possible in dealing competently with knowledge. Thus, different forms of knowledge can be 
distinguished, which are relevant to students for successfully coping with university structures and demands. This article differentiates between organizational, academic, and skills knowledge. Organizational knowledge refers to any knowledge that targets the progress of studies and finding one's bearings within the organization, for instance, how students draw up their class schedule; when classes begin; how often examinations may be repeated, etc. Academic knowledge, for instance, refers to the awareness of at least three different bibliographical references, various classics of the field, and composition and structure for a written paper. Finally, skills knowledge implies the knowledge about one's own skills and capabilities and conscious self-assessment. For example, whether students think they have the required competencies, finding and citing academic literature, or being able to excerpt a text correctly as well as to feel capable of preparing appropriately for one's examinations.

Our application aims at developing "practical awareness" (Giddens 1988) and making knowledge available as a resource for pragmatic action. Because the actors cannot always reflect on every action, the application reduces the complexity of reflection by constructing, pre-structuring, and making students aware of the objects of reflection in a medial way within time-dependent reflection intervals. At the same time, the students' knowledge levels are accessible for organizational development.

\subsection{Reflection in and on Action: Schön's "Reflective Practitioner"}

The direct "reflection-in-action" and "reflection-on-action", i.e., after it has been carried out, are understood as distinct reflection processes based on Donald A. Schön's work on the "Reflective Practitioner" (Schön 1983; Wyss 2008). The application operationalizes reflection-on-action by asking the actors questions and, thus, helping them to organize, express, and think through their (action) knowledge. This is the prerequisite for the actual awareness of knowledge, its analysis, and its communication to other people. In this way, knowledge is first made accessible as the basis for action to reorganize and potentially manifest change (Altrichter and Posch 2007). The reflection competency itself thus becomes the condition for managing complex action challenges and, at the same time, the possibility for externalizing this knowledge (in language).

This form of reflection is based on close-ended questions, since the content is based on material and criteria, which can be mapped. Open-ended questions, to which students can reply in the form of text input, supplement the possibilities for reflection. Finally, the questions operate on three different reference levels, namely the micro-, meso- and macro-level (see for education Fend 2001). The micro-level refers predominantly to the concretely acting actors, to their personal experience, and to everyday generative prior knowledge. The meso-level comprises all broader actions in the organizational context of university and the introductory phase. The conditions in higher education policy are relevant at the macrolevel, which influences the layers below.

The Reflect.UP mobile application draws on specific (interaction) situations, that participants negotiate and assess. From this perspective, courses, a visit to the library, or the joint students' lunch can be stimuli for individual learning, as well as important knowledge resources. The confrontation with these situations generates information on topics, which are highly relevant for students. Therefore, the students' experiences as "experts in everyday university life" can be utilized for the positive modification of the organizational structures. In this way, the mobile application constitutes an interface between the students and the university, which is equally interested in studies commencing and progressing, and both parties can benefit from one another with the mediation help of Reflect.UP. 


\section{Analyzing Study Regulations: From Module Objectives to Reflective Questions}

The core challenge of the project was to design reflective questions, so that they seem neither random nor overly technical or formal and, nonetheless, refer specifically to the required contents of the introductory phase. Following Baumert and Kunter's model of the "professional competency to act" (2006), four relevant competency aspects were identified to analytically structure the reflective questions:

- Professional knowledge comprises declarative, procedural, and strategic knowledge. For this project, a limitation to specialized knowledge and organizational knowledge suffices.

- Beliefs and values include, inter alia, knowledge about academic standards and understandings of roles towards professors and fellow students.

- Motivational orientations influence personal and professional attitudes and decisionmaking.

- Self-regulating skills mean knowledge about one's own skills and capabilities, as well as conscious self-assessment, for instance, when dealing with problem situations.

Originally, the model of Baumert and Kunter was designed as a competency framework for teachers in the higher education system, but this format was applied to the analytical framework of the reflective questions. The study regulations, specifically the module descriptions for the fields involved, were used as a data basis for the reflective questions. In the first step, the module descriptions were investigated to extract the included learning objectives. Out of the previously extracted learning objectives, suitable reflective questions were derived, grouped, and sequenced according to the different stages of the first semester. The objectives of the field, as well as the module recommendations for the first semester, were examined. This resulted in a total of 18 recommended module units and descriptions from management economics, sociology, political economics, political science, and political administration and organization. Subsequently, the overlapping objectives of the module units from the first semester were extracted as a qualitative content analysis and compared in the form of a theme matrix (derived by drawing up a profile matrix) (Kuckartz 2012). The profile matrix covers all module units considering all courses of studies. As a result, the matrix is on a very abstract level and is used as a theoretically and generalized starting point to create competencies including all module units for all courses of studies (Table 1).

This approach enables the adoption of a case-by-case perspective and the creation of thematic access. For the intended outcome of the latter comparative approach, students are principally meant to:

- understand the concepts, theoretical and methodological basis, and objects of the field

- acquire basic knowledge about theories, methods, processes, participants, institutions, and problems

- gain aware of classic specialist texts

- acquire a basic understanding of the subject as a science, as well as classical social theory approaches and issues

- gain competencies for the analysis of social structures and processes

- have the capacity to use basic specialist terminology in a reflective way

- have the capacity to critically measure specialized perspectives and positions. 
Table 1 Extract of the profile matrix that shows the identified similarities for the whole studies

\begin{tabular}{|c|c|c|c|c|c|}
\hline & \multicolumn{5}{|c|}{ Courses of Studies } \\
\hline & $\begin{array}{l}\text { Management } \\
\text { Economics }\end{array}$ & Sociology & $\begin{array}{c}\text { Political } \\
\text { Economics }\end{array}$ & $\begin{array}{c}\text { Political Sci- } \\
\text { ence and } \\
\text { Administration }\end{array}$ & $\begin{array}{c}\text { Political Science, } \\
\text { Administration } \\
\text { and Organization }\end{array}$ \\
\hline $\begin{array}{l}\text { Professional } \\
\text { knowledge }\end{array}$ & $\begin{array}{l}\text { Acquisition of } \\
\text { entrepreneurial } \\
\text { thinking }\end{array}$ & $\begin{array}{l}\text { Understanding, } \\
\text { comparing and } \\
\text { applying socio- } \\
\text { logical theories } \\
\text { and methods to } \\
\text { social processes }\end{array}$ & $\begin{array}{l}\text { Acquiring the } \\
\text { ability to apply } \\
\text { the methods and } \\
\text { insights }\end{array}$ & $\begin{array}{c}\text { Acquiring } \\
\text { knowledge of } \\
\text { the traditional, } \\
\text { democratic basic } \\
\text { theories }\end{array}$ & $\begin{array}{l}\text { Knowledge of the } \\
\text { political-adminis- } \\
\text { trative structure } \\
\text { and processes at } \\
\text { different system } \\
\text { levels }\end{array}$ \\
\hline $\begin{array}{l}\text { Academic } \\
\text { knowledge }\end{array}$ & $\begin{array}{l}\text { Understanding } \\
\text { administrational } \\
\text { problems }\end{array}$ & $\begin{array}{l}\text { Training broad- } \\
\text { based, critical } \\
\text { thinking, deci- } \\
\text { sion making, } \\
\text { and social skills } \\
\text { that are well- } \\
\text { grounded in so- } \\
\text { cial theory }\end{array}$ & $\begin{array}{l}\text { Acquisition of } \\
\text { specialized } \\
\text { knowledge }\end{array}$ & $\begin{array}{l}\text { Acquisition of } \\
\text { scientific basics }\end{array}$ & $\begin{array}{c}\text { Acquiring } \\
\text { knowledge of the } \\
\text { traditional demo- } \\
\text { cratic basic theo- } \\
\text { ries }\end{array}$ \\
\hline $\begin{array}{l}\text { Self-regu- } \\
\text { lating skills }\end{array}$ & $\begin{array}{c}\text { Making respon- } \\
\text { sible and appro- } \\
\text { priate decision }\end{array}$ & $\begin{array}{l}\text { Enabling scien- } \\
\text { tifically based } \\
\text { judgment to act } \\
\text { responsibly }\end{array}$ & $\begin{array}{c}\text { Developing } \\
\text { communications } \\
\text { and team skills }\end{array}$ & Soft skills & $\begin{array}{l}\text { Training decision } \\
\text { making and social } \\
\text { skills }\end{array}$ \\
\hline
\end{tabular}

In addition to these perspectives for specific majors, the basic understanding of how organizations function, as well as general knowledge about the most important organizational theories and the differentiated use of the concepts micro-, meso- and macro-levels are also included. The first-semester students are as well intended to acquire knowledge of scientific working. This comprises the following abilities:

- to examine an academic paper and produce a structured academic analysis

- to work in a team

- to grasp, systematically analyze, reflect critically on, and discursively develop complex issues

- to develop research questions and designs independently as well as to identify appropriate methods and processes to work on them.

In the next step of the qualitative content analysis, the similarities between the learning and competency objectives of all subjects were investigated. The extracted competencies were clustered based on the four aspects of Baumert and Kunter. The dimensions, motivational orientations, and values and beliefs primarily appear in the study regulations as professional knowledge, for instance, when examining value orientations and attitudes in a certain field.

This step enabled the development of primarily closed and open reflective questions based on the profile matrix. Afterwards, the developed questions were assigned to the four relevant competency aspects of Baumert and Kunter and subcategories were developed concurrently to concretize student's required competencies. For quality assurance purposes, those responsible for the modules were consulted with regards to the results and then validated them. Table 2 illustrates a subset of the derived reflective questions and the associated (sub)-competency classifications based on Baumert and Kunter. 
Table 2 Competency aspects and reflective questions of the courses of studies of the Faculty of Economics and Social Sciences at the University of Potsdam

\begin{tabular}{|c|c|c|c|c|c|c|c|c|}
\hline & \multicolumn{4}{|c|}{ Professional knowledge } & \multicolumn{3}{|c|}{ Self-regulating skills } & \\
\hline & $\begin{array}{l}\text { Organizational } \\
\text { knowledge }\end{array}$ & $\begin{array}{r}A \\
k n o\end{array}$ & $\begin{array}{l}\text { ion } \\
\text { edge }\end{array}$ & $\begin{array}{l}\text { Specialized } \\
\text { knowledge }\end{array}$ & $\begin{array}{l}\text { Critical re- } \\
\text { flection/self- } \\
\text { awareness }\end{array}$ & Self-care & $\begin{array}{l}\text { Time manage- } \\
\quad \text { ment }\end{array}$ & \\
\hline \multirow[t]{3}{*}{ 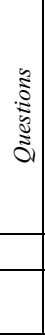 } & $\begin{array}{l}\text { Do you know } \\
\text { there's a deadline } \\
\text { to sign up for the } \\
\text { courses? }\end{array}$ & $\begin{array}{r}\text { W } \\
\text { wou } \\
\text { appr } \\
\text { yol } \\
\text { ques } \\
\text { lated } \\
\text { study } \\
t\end{array}$ & $\begin{array}{l}\text { om } \\
\text { lyou } \\
\text { ch, if } \\
\text { lave } \\
\text { ns re- } \\
\text { your } \\
\text { egula- } \\
\text { ? }\end{array}$ & $\begin{array}{l}\text { Do you know } \\
\text { how a paper in } \\
\text { your academic } \\
\text { field is struc- } \\
\text { tured? }\end{array}$ & $\begin{array}{l}\text { How do you } \\
\text { spend your } \\
\text { free time? }\end{array}$ & $\begin{array}{l}\text { With whom } \\
\text { do you have } \\
\text { lunch at Uni- } \\
\text { versity? }\end{array}$ & $\begin{array}{l}\text { How good is } \\
\text { your time man- } \\
\text { agement? }\end{array}$ & 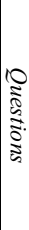 \\
\hline & \multicolumn{4}{|c|}{ Academic knowledge } & \multicolumn{3}{|c|}{ Beliefs \& values } & \\
\hline & \multicolumn{2}{|c|}{$\begin{array}{l}\text { Basic academic } \\
\text { knowledge }\end{array}$} & \multicolumn{2}{|c|}{$\begin{array}{l}\text { Knowledge about one's } \\
\text { own learning behavior }\end{array}$} & \multicolumn{3}{|c|}{$\begin{array}{l}\text { Basic individual attitudes and convictions to- } \\
\text { wards studying }\end{array}$} & \\
\hline 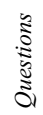 & \multicolumn{2}{|c|}{$\begin{array}{l}\text { Do you feel able to cite } \\
\text { literature in the correct } \\
\text { professional manner? }\end{array}$} & \multicolumn{2}{|c|}{$\begin{array}{c}\text { How do you prepare for } \\
\text { exams? }\end{array}$} & \multicolumn{3}{|c|}{$\begin{array}{c}\text { What do you expect of your study? / What are } \\
\text { your expectations of your study? }\end{array}$} & 5 \\
\hline
\end{tabular}

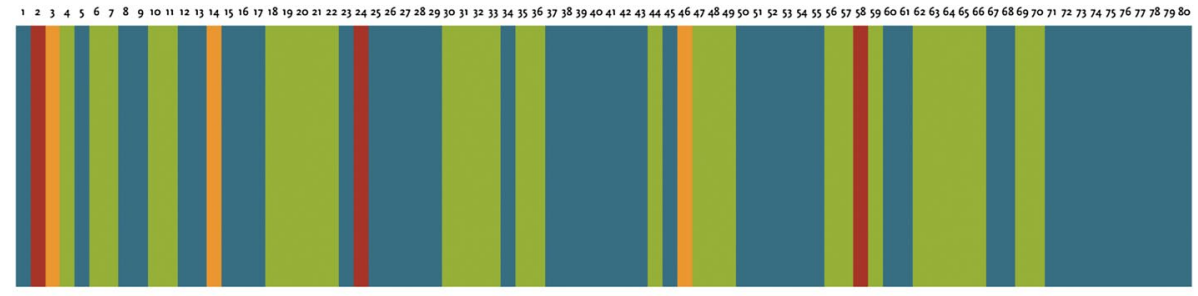

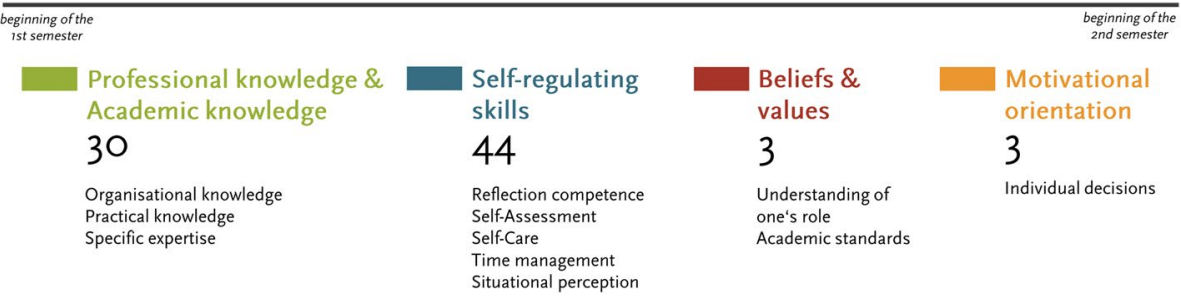

Fig. 2 The first draft of the 80 questions for the first semester color coded according to the categories professional and academic knowledge, self-regulating skills, beliefs and values and motivational orientation

By carrying out this process for all courses of studies, a universal competency framework across departments (Dehne et al. 2016) arises, one that can gradually be expanded to the entire university. Due to the described process, over 80 reflective questions were generated, addressing topics for the first semester. The sequence of the questions and their thematic focus for the Faculty of Science according to Baumert and Kunter (2006) is shown in the following Fig. 2. 


\section{Study Organization, Expectation Management, and Reflection: The Reflect.UP app}

The application attempts to foster students' reflective skills as a prerequisite for professional competency and to improve the progress of students' commencing their studies. To this end, the app engages a three-pronged approach:

1. Scheduling Overview The application is intended to facilitate students' orientation by bundling, making available, and reminding them in a timely manner of all deadlines relevant to their studies (registration periods, deadlines, examinations, etc.) during the first two semesters. This is also supported by the device and course-specific push messages.

2. Situational Reflection At irregular intervals, reflective questions are pushed to the device that refer to the knowledge and skills required in the introductory phase of studying and to the three areas: organizational knowledge (Where do I get a library card?), academic knowledge (How do I read a table?) and skills knowledge (Can I do what is required of me, and does what is required fulfill my expectations?). Social aspects, such as general satisfaction with studying and integration into students' learning and work groups, are also made a subject of discussion.

3. Knowledge The feedback produced by answering the reflection questions, e.g. on students' expectations and competency assessments or on context-related satisfaction, is intended to contribute to a more direct relationship between the university and students. The results and the data from the open feedback form are used, if applicable, in order to improve the structure of studies. Furthermore, by taking up the collected data, constructive feedback can be given to those responsible for the specific introductory course or academic phase and the students themselves.

By means of these three levels, not only are reflection processes shaped, but the possibility to mirror students' introductory phase is also presented. The overarching objective of the application is to professionalize the students' behavior, as it contributes to developing a scientific culture of reflection and bring academic thinking, where everyday orientation and scientific knowledge flow together, closer to the students (Ludwig 2012). The structural position and "task of the introductory phase is to recommend this skill of reflection to the students for their own actions while studying" (ibid.). The aim of developing the Reflect.UP application is to contribute to these efforts, as well as to utilize situational problems of action as a resource for organizational development.

\subsection{Generic Moodle Course to Support the Students}

For maintaining the data (i.e., reflective questions, dates, feedback), it was explicitly decided not to implement an independent authoring platform. This would have entailed unnecessary duplication of functions, as well as an additional system, which would require additional support. Instead, the learning management system Moodle was chosen for use, as it was already in place at the University of Potsdam. Those responsible for courses of study can comfortably enter and administer dates and reflection questions in a familiar system. In addition to the administration of dates and the feedback and reflection questions, there are further advantages for using Moodle, such as an existing user administration, extensive possibilities for 
expansion within a modular plug-in structure, and basic functionalities to conduct courses. Individual courses can be created for a wide range of courses of study, which can be used either continuously for one cohort or specifically for one course of study. This enables a continuous use of the course and mobile application throughout the course of studies. The calendar within the individual Moodle course can be used for specific dates concerning certain courses of study. Here, dates can be furnished with a title and a more detailed description. Besides individual dates, usual recurring dates or time spans can be entered.

The centerpiece of the application, the reflection questions, is implemented with the help of the Moodle feedback module. There are various formats available (free text, multiple choice, single choice) to address a range of levels of reflection and to gather situational data. Those responsible for courses of studies can be examine the anonymous answers and export them for further processing. Furthermore, it is possible to extend the classic, linear reflection questions with so-called conditional questions. This means that, based on a given answer, a different subsequent question is displayed next. This can be very helpful if the person responsible for the course of study wants to differentiate between possible answer options. At the end of each reflection question block, it is possible to provide further details, links, or feedback to the user.

Export and import functions enable the further use of reflection questions that have already been developed. For targeted push messages, the course offers a Moodle block, ${ }^{11}$ through which short messages can be sent to the users, in order to call their attention to new reflection questions and dates, or to inform them about urgent messages. Overall, the communication path between the study organization and the students has been drastically reduced, and the contact points between these two groups have been increased.

In order to address international study courses, Reflect.UP supports internationalization. Thus, dates, reflection questions, and push notifications can be created and maintained in different languages with the Moodle filter "Multi-lingual Content". ${ }^{12}$ Meanwhile, German, English, and Spanish are supported languages. There are plans to extend the support to French. In order to continue to use the functions addressed in the mobile application, it was necessary to create new interfaces for the feedback module and for the course-specific calendar. A web service $^{13}$ written for Moodle on the basis of the local plug-in type ${ }^{14}$ enables the exchange of the reflection questions between Moodle and the application, its course-specific persistence in the Moodle database (after completely answering in the app), preparation of the calendar entries, and conveying free text feedback to the course's respective feedback forum. The transmission of push messages is executed through a separate web service (through use of the platform independent push service AirNotifier ${ }^{15}$ ) that, in turn, distributes the message to the corresponding Apple or Google interfaces. Figure 3 shows three exemplary views.

The authentication of the web service is executed via the already existing Moodle account, i.e., users only need to log into the app once in a personalized manner. However, the display of the answered reflection questions within the Moodle course is anonymous for the lecturer, but not stored anonymously within the database. Thus, it is impossible for the course instructor to identify students. In turn, feedback occurs on a personalized level; thus, those responsible for courses of study can consult individually with the students based on free text feedback (Fig. 3c) and, if necessary, resolve questions or issues promptly.

\footnotetext{
11 https://github.com/University-of-Potsdam-MM/reflect-block_pushnotification (last retrieved 02/19/19).

$12 \mathrm{https} / / /$ moodle.org/plugins/filter_multilangsecond (last retrieved 02/19/19).

13 https://github.com/University-of-Potsdam-MM/reflect-local_reflect (last retrieved 02/19/19).

14 https://docs.moodle.org/dev/Adding_a_web_service_to_a_plugin (last retrieved 02/19/19).

15 https://airnotifier.github.io/ (last retrieved 02/19/19).
} 


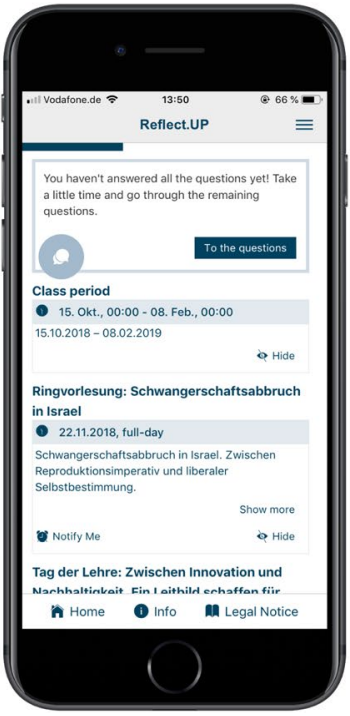

(a)

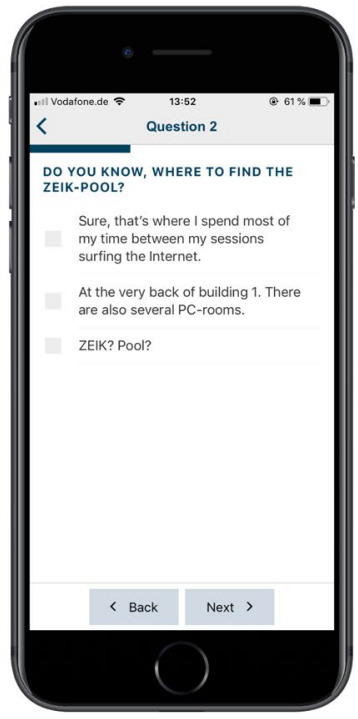

(b)

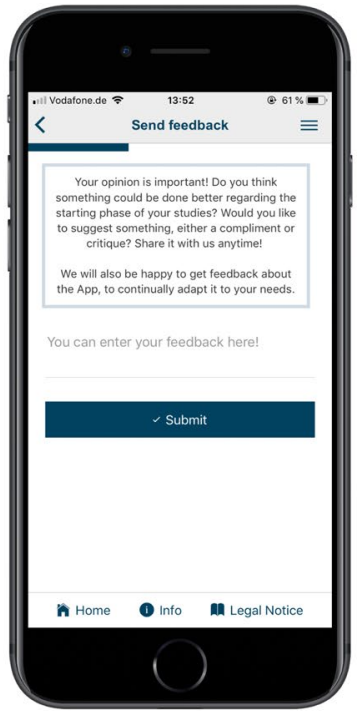

(c)

Fig. 3 a Landing page with dates and a link for the reflection questions. b The second reflection question out of 4 , addressing the place of the computer pools. $\mathbf{c}$ The view containing the free text feedback form

\subsection{Interface, Functions, and Architecture}

The mobile application Reflect.UP has three basic views, which are depicted in Fig. 3. When the application is launched, users first receive an overview of their next dates and possible reflection questions (Fig. 3a) that are still to be answered. If there are more than three dates, a second view shows additional details. Answering the reflection questions (Fig. 3b) can take place at multiple sessions, so that users have the possibility to continue answering questions at a later time. For this purpose, the questions and answers are cached in the app. If new dates or reflection questions arrive, users are informed through the push function in a time-controlled manner. Because only three dates can be displayed on the start screen, a separate view was implemented, which lists all available dates. Based on the given user feedback, two additional functions were added. First, the user can filter and hide specific dates and deadlines. The second function implements a reminder, with which a user can set an alert, which triggers a local notification and reminds the user, either a day or some hours ahead, of the pending date or deadline.

For the implementation of the mobile application Reflect.UP, ${ }^{16}$ the $\operatorname{Cordova}^{17}$ and Ionic $^{18}$ framework are used, to design a hybrid application for many platforms at relatively

\footnotetext{
16 https://github.com/University-of-Potsdam-MM/Reflect.UP (last retrieved 02/19/19).

$17 \mathrm{https} / / /$ cordova.apache.org/ (last retrieved 02/19/19).

18 https://www.ionicframework.com/ (last retrieved 02/19/19).
} 
low cost, in order to digitally support as many first-semester students commencing their studies as possible. Technologies such as HTML5, CSS3, and JavaScript are used to structure and modularize the application (Kiy et al. 2015). Cordova acts as a container and bundles all source code. For device interaction (i.e. sensors, local, and push notification) Cordova offers a wide range of API-based plugins. Using a hybrid application, only one version of source code must be maintained, which simplifies further developments through a reduced training period. Even small style and content changes can be easily realized by non-developers.

While facing a growing desire to cooperate with other universities, the Reflect.UP had to meet additional requirements for various universities, faculties, degree programs, and study courses. It resulted that the existing manner to build a dedicated version of Reflect. $U P$ for each stakeholder would have been exorbitantly expensive. Thus, a modular design for the architecture of the application was developed, and, as a result, not all users have to access to the same content to the same extent, or for instance, the capacity to build a new application. This opens up the possibility for differentiating user groups within the app and assigning them to the individual institutions, departments and subjects.

On an institutional level, this approach provides the possibility for customizing Reflect. $U P$ according to the specific needs of an institution, for example to meet the individual corporate identity, support different authentication mechanism (LDAP or Single-Sign-On) and to implement individual user consents or the federal data privacy regulation. For the implementation of several study courses within one institution, it was more practicable to implement a type of switch. Thus, when launching the application, the user can choose the relevant field (see Fig. 4 lower left application). Necessary details, like the personal Moodle course, the name and description of the course and the contact information of those responsible for courses of studies can be configured at runtime. This ensures more flexibility for executing the standard scenarios. The Fig. 4 below summarizes the organizational components available within each Moodle course (reflective questions, feedback forum,

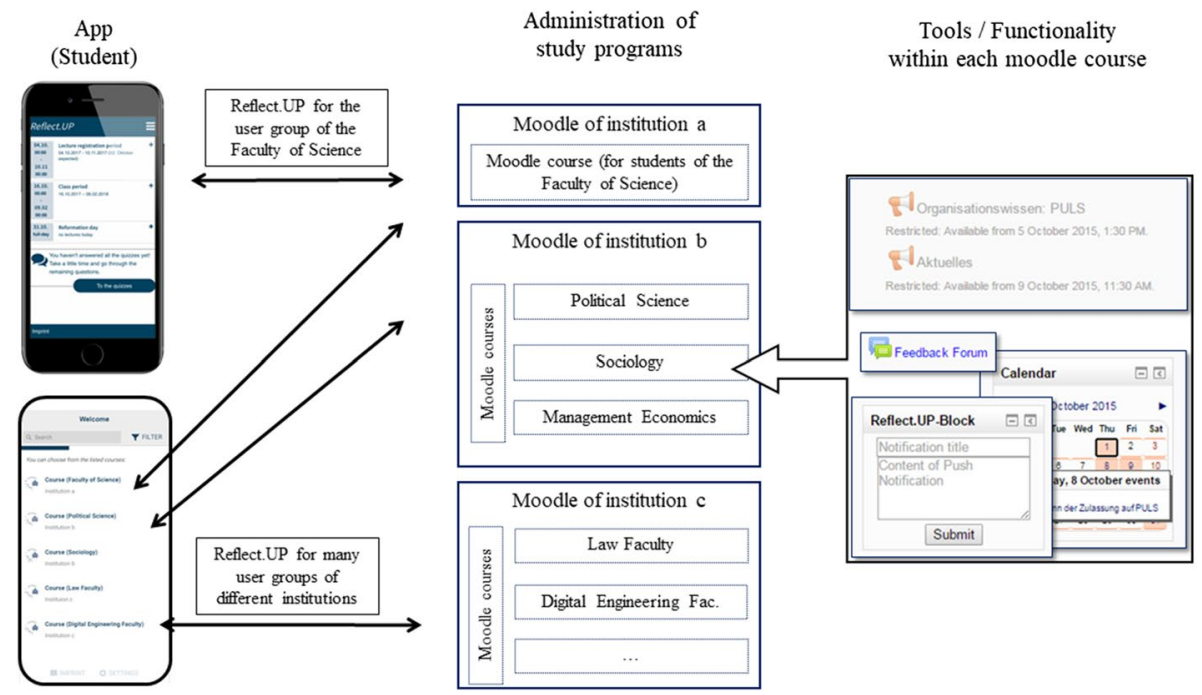

Fig. 4 Architecture overview of the mobile application with the associated Moodle course of various institutions and the according functions. The upper application is linked to one institution and one course, the other with three institutions, where institution $b$ and $c$ offer various courses for freshmen 
push messages and the calendar for appointments). Every institution can group the freshmen according to their needs. Some group them by the faculty affiliation, by the courses of studies or form groups addressing specific needs (e.g. exam students in the Law Faculty).

For a short technical evaluation of the Reflect.UP application, a group of 21 students consisting of student tutors and freshmen were anonymously surveyed using a three-part questionnaire. The questionnaire contained open and closed questions that referred to both the technical functioning and the usefulness of individual elements of the application. Overall, the test group came to an exceedingly positive conclusion. In principle, 20 of 21 interviewees found the idea of a module-accompanying mobile support a good idea. For 18 testers, the usability of the application was described by to be intuitive, while three respondents judged the app to be rather complicated. Regarding the questions already programmed, there was also a clear vote. In the opinion of 20 of the 21 students surveyed, the questions were suitable to encourage new students to reflect. Rather more critical, on the other hand, were the assessments of the implemented help texts. Almost two thirds of the interviewees thought that there were not enough help texts and detailed information made available. For the developer team, other future work assignments can be derived from answers to the open questions. A few examples are noted below, referring to the question on additional functions, which the test users wished for in the future:

- Implementation into the existing mobile application of the University of Potsdam called Mobile.UP.

- More questions that relate to everyday student life and organizing one's studies.

- Additional questions specific to certain courses of study, as well as questions on how to successfully take part in specific classes or connect with fellow students.

In conclusion, the overall impression of the application Reflect.UP was evaluated by two students as "very good," by 13 students as "good," by five students as "ok," by one student as "poor," and by no one as "very bad."

\section{Empirical Results}

\subsection{Insights into Economic and Social Sciences Students' First Semester}

The first strategic implementation, establishment, and embedding of the app into the introductory phase occurred with the Faculty of Economics and Social Sciences ${ }^{19}$ at the beginning of the winter semester 2015/2016. The Faculty was selected due to its structured introductory phase, which is predestined for this matter through the "Basic Academic Skills" module and its sub-modules "Methods of Scholarly Working and Writing" and "Self-Reflection and Planning." The latter contains introductory tutorials for first-semester students in management economics, political economy, political science, business computer science, administration, and sociology, and was conducted in a compressed format immediately before the lecture period.

\footnotetext{
19 Accompanied by preannouncements in the university media like the e-learning newsletter ("Portal") and the home page of the University of Potsdam, as well as a wide range of links on university websites with multiplier effect.
} 
The application was treated as an independent, substantive component in all students' introductory tutorials, in order to convey its significance and benefits to the 600 participating students. The use of the application and the response to feedback questions is always voluntary. This also leads to a different number of responses of the individual feedback questions. The application starts where the content for the introductory tutorials on selfreflection and planning ends. With the help of the application, regular self-assessment of the students' satisfaction concerning their own orientation, performance, and skill level is possible throughout the introductory two semesters.

More than 500 students (almost $90 \%$ of the first-semester students physically present) downloaded the app from the GooglePlaystore or Apple iTunes either before the beginning of the semester or within the first three weeks. This result far exceeds the originally envisioned rate of $25 \%$. When the app was introduced, 250 students, i.e. more than $50 \%$ of those who installed the app, actively participated in answering the questions.

The calendar function played an important role for the students in orienting themselves and structuring the semester; this turned out to be the right incentive for the long-term use of Reflect.UP. Twelve percent desired further clarifications on the appointments, a reminder function, and date filters specific to courses of study. This, in turn, was implemented accordingly.

The active participation figures are consistently positive. On average, 60 students answered the first 20 questions presented. However, the rate of responses fell continuously over the entire semester; this result is compatible with the basic idea of the app. That is because the focus lies on individual reflection, not on the actual response to the questions in the sense of an evaluation. The style of the asked questions is therefore aim to inform about support offers, about ways how to cope with stress or for possibilities how to prepare exams properly. These are conducted on an obligatory basis for each course and are thus complementary to the app and other forms of survey.

At the beginning of the semester, the students were asked whether they had looked at the course catalogue, whereupon 172 confirmed that they had already drawn up their class schedule. In the first week of the semester, only 32 had just skimmed the seminars on offer, and only 17 had not thought about it yet at all. In the 120 free-text answers relating to the questions on what the students intend to do in the first semester, it became clear that in addition to the solid organization of the students, very strong aspirations towards selfoptimization, intentions to be high performers, and a pronounced will to succeed could be observed among them. The freshmen expected "diligence" from themselves and think about on own weaknesses; after high school they really want to start "hitting the ground running with issues that I am (they are) really interested in," "passing all examinations with at least 2.7," or "getting by very well (and) not wasting any time." Both time management and a fast integration are important issues for them, but also private projects were mentioned like "reconcile sports and studies." (see Fig. 5).

This contradicts with 38 entry fields about what is still unresolved at the end of the first week. In this case, uncertainties and concerns about "good time management" $(\mathrm{N}=5)$, "doing something wrong in the mid- to long term" $(\mathrm{N}=7)$, or "having selected the right course of study" $(\mathrm{N}=4)$ in the first place dominate. Some of these free-text answers consist of several sentences; this underlines the relevance of the addressed content.

In the middle of the semester, the questions were a target of reflection on the choice of the program of studies as well as initial assessments of self-organization skills, such as time management. Particularly those studying Political and Administrative Sciences and Management believe that they have strong job market prospects due to their choice of study. Regarding self-management, 32 students $(68.1 \%)$ indicated that they would be either 


\section{Faculty of Economics and Social Sciences in winter semester 15/16}

( $N=209)$

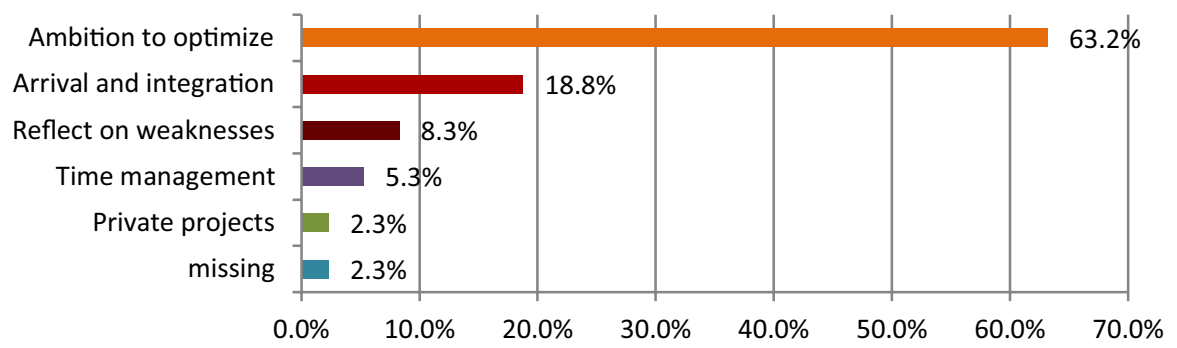

Fig. 5 Analysis of the answers to the question of what the students intend to accomplish this semester

"doing too much" or "not able to say no". Only eleven students (23.4\%) were satisfied with their time management. This result is in line with various open feedback fields in which twelve students explicitly desired support offerings to learn time management.

Towards the end of the semester, questions become more frequent on specific skills and abilities, as well as general self-assessments. For example, $90 \%$ of the students $(\mathrm{N}=32)$ could not name any research databases, and only $13.3 \%$ students $(\mathrm{N}=4)$ definitively knew how an academic paper in their field should be structured. Of the students, $36 \%$ described exam nerves as a personal issue. Furthermore in second study, $54 \%$ of the students $(\mathrm{N}=60)$ indicated that they are satisfied with their studies but imagined them differently.

This cross-section of questions and feedback clearly reflects issues and points of resistance for students starting university. Occasionally, improvements were suggested, such as a more intensive "examination of the study regulations" during the introductory phase. Nevertheless, praise was also given that, for example, the "thirst for knowledge was quenched", and students were "well advised". These two important pieces of information create possibilities for action and predictability for (both) students and university.

\subsection{New Insights and Comparison}

After completing the first strategic implementation, establishment, and embedding of the app into the introductory phase at the Faculty of Economics and Social Sciences, the Reflect.UP app was published for all remaining faculties of the University of Potsdam in the winter semester 2017/2018.

The experiences during first semester stimulate the Reflect.UP team to critically look at the time and content-related sequencing of the questions. The students' specific subjectrelated requirements are the guiding factors for which the sequence of questions may to some extent seem too heterogeneous. To develop the best tools, however, additional rounds need to occur. In these reflection loops based on experiences of previous results, new or different study specific topics are integrated, and questions are partly re-adjusted. An important finding of the first structural embedding of the application was that the diversity of the organizational structures of the faculties does not allow to simple "copy and paste" the app with the predesigned question catalogue from one faculty to another. Each faculty has individual needs and different characteristics of freshmen. Therefore, the competency aspects and reflective questions of Faculty of Economics and Social Sciences were used as 


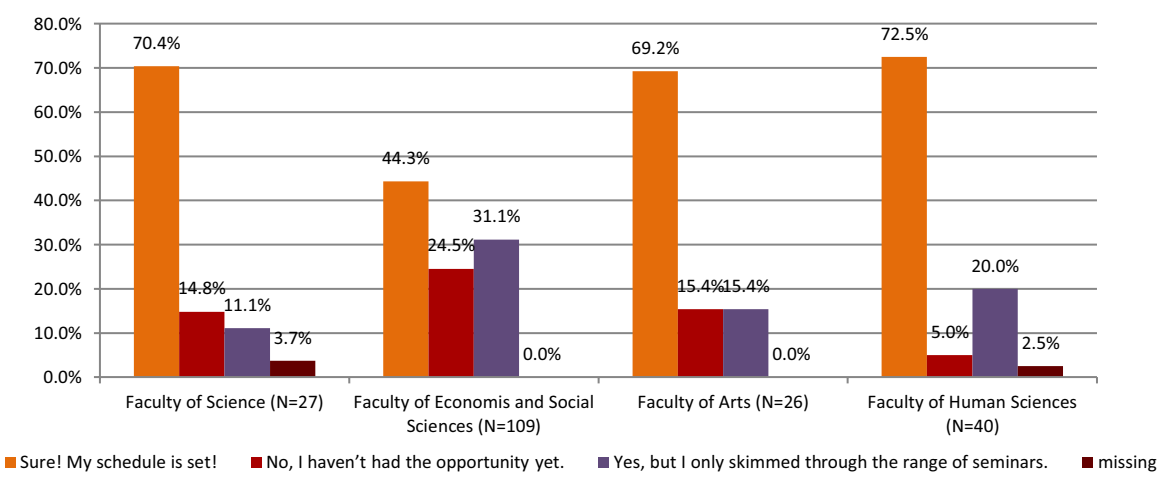

Fig. 6 Results to the question "Have you already taken a look at the course catalog?"

a blueprint to be individualized by each faculty. The implementation of Reflect.UP for all faculties allows for the first time the comparisons between groups of student freshmen.

An impression according to the question, whether the freshmen have already looked at the course catalog, is shown in Fig. 6. While almost $70 \%$ of the freshmen already set their schedule in the Faculties of Science, Arts and Human Science, nearly half of the freshmen in the Faculty of Economics and Social Sciences only skimmed through the range of seminars or had not had the opportunity yet. Since the question is offered to all faculties at the same point of time, it leads to the consequence that for the next introductory courses at the Faculty of Economics and Social Sciences the focus must be set on course planning and scheduling first semester courses.

Almost all students get sufficient support in the first semester in registering for their courses. However, the results indicate a problem within the Faculty of Economics and Social Sciences. Maybe the offer to freshmen was unsatisfying or it is difficult to find the necessary materials (course catalogue and study regulations). With the help of the app those problems become transparent and can be addressed with special support offers.

Due to the fact the app has been offered to all freshmen of the Faculty of Economics and Social Sciences for the last three years, gives the opportunity to compare freshmen over this period of time. The results presented in Fig. 7 indicate that the last cohort feels more capable of writing an academic paper (75\%) compared to only $23.1 \%$ one year before and to $16.7 \%$ in the winter semester $2015 / 16$. This might also be a result of establishing a structured introductory phase, in which Reflect.UP is embedded.

In order to develop initial hypotheses on the individual worlds of experience when starting university, one important methodological building block is the use of the

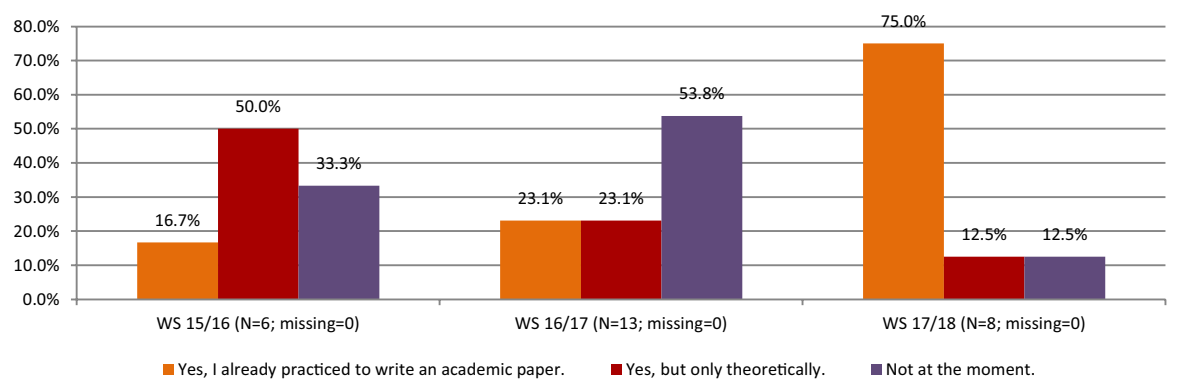

Fig. 7 Results to the question "Do you feel capable of writing an academic paper?" sorted by year 
analytical strategy of "coding and categorizing" (Strauss and Corbin 1996). By the use of the grounded theory, longer free-text answers are broken up and summarized as categories. All results are first redacted by the Reflect.UP team and subsequently processed in the form of descriptive and qualitative evaluations, which are used in the reporting activities by the university's Center for Quality Development. Finally, the results are provided as feedback to the faculty and the program coordinators. These results are discussed and evaluated in the group of academic deans and quality managers and in the departments' curriculum commissions. As a result, both short-term actions like spontaneous tutorials (e.g. intervention for the derived results from Fig. 6) and long-term actions like adjustments of the introductory phase and the design of the studies themselves can be taken as actions.

Even though the following results are not statistically representative, we get the impression that only a few of the freshmen are able to motivate themselves with the help of study groups (e.g. Figs. 8, 9). Furthermore, it seems that study groups play merely a role in the Faculty of Science (STEM-fields). Only every eighth freshmen considers a learning group more efficient compared to learning for himself. Therefore, the aspect of freshman learning

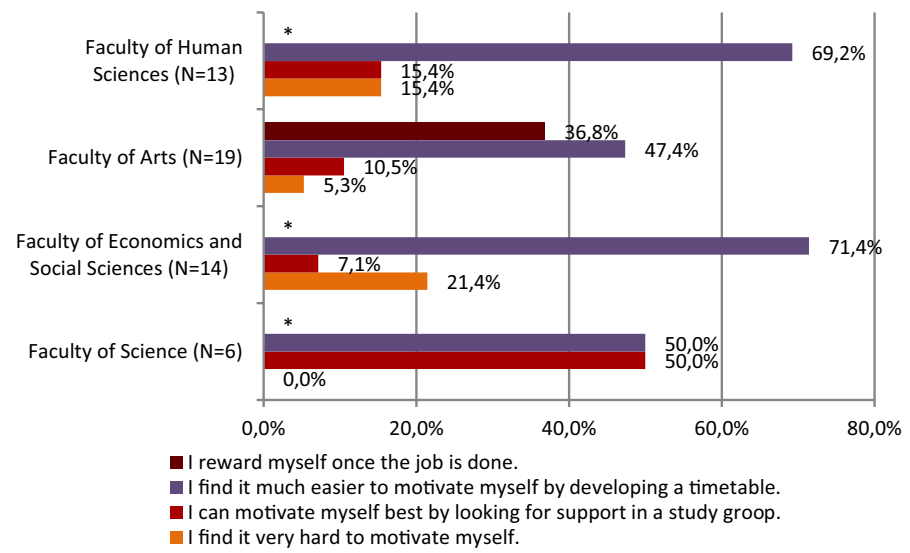

Fig. 8 Results to the question "How do you motivate yourself to study?" (*this answer was only available in the Faculty of Arts)

Fig. 9 Results to the question "Did you try to prepare for tests with a learning group" in winter semester $17 / 18$

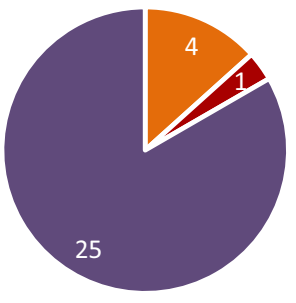

- Yes, it's much more efficient than learning alone.

- I tried, but it did not work well.

- No, I prefer learning allone. In a learning group you only distract each other. 
communities (FLC) has to be addressed in the next preparation phase of freshmen. Since FLCs can play a crucial role for academic performance (Hotchkiss et al. 2006) the building process of FLCs must be included and especially accentuated in the introductory phase for all faculties.

The rate of students who find it hard to motivate themselves (e.g. Fig. 8) is surprisingly high in the Faculty of Economics and Social Sciences (even it is close to the 18\% of Heublein et al. 2009). As a result, it is proposed to stimulate explicitly the implementation of FLCs in the introductory phase (WS 19/20) of the faculty.

Although most students live in Berlin, only $11 \%$ consider their travel time to be a personal "time thief". For every third social media is a time problem. This problem can be tackled to some extent by providing student information through different social media channels. It is surprising, that the student job does not count as a form of wasted time for students. Former research (Heublein et al. 2012) indicated the lower relevance of student jobs for conducting studies. Either student freshmen have less often a job, or they do not count the job as a waste of time due to existential necessity. Once again, the motivation deficit is a major "time thief" for $12 \%$ of the students (Fig. 10).

The app use at the Law Faculty represents a special case, as this faculty offers only a single major course. The four other faculties offer a variety of courses. Thus, no subjectspecific questions can be addressed to the participants, since for example, a sociologist does not necessarily have economic knowledge but both are enrolled to the Faculty of Economics and Social Sciences.

At the Law Faculty, very specific questions are asked regarding juridical knowledge or the organization of the courses. Due to the low flexibility in the course schedule, students have similar structured days and face similar problems. The app is very well received and is even used as a standardized communication channel. The Reflect.UP perfectly fits in the communicational gap between students and study organization. Especially the support of other structures of first term weeks changes the usability of the application. This results in a new approach of using the application at the Law Faculty. The application is used as a means of communication for students during their legal clerkship training. This opens the

Travel time to the university

Follow-up university work

- Social media

Housework, cooking etc.

- General media consumption

Social life, family, sports

Student job

Disorganization, lack of motivation

None

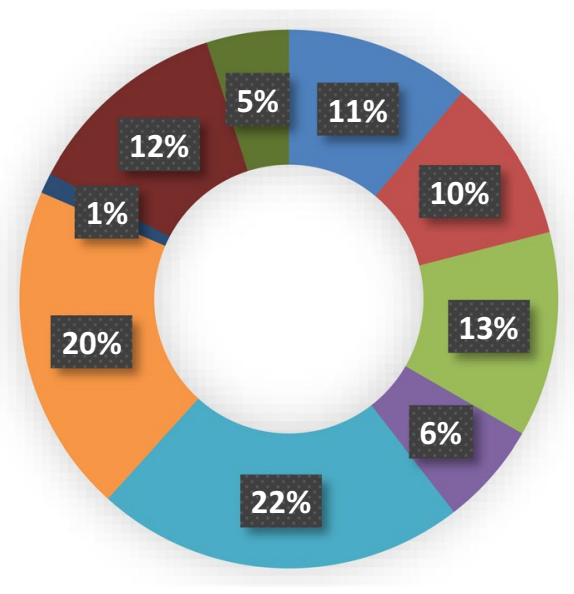

Fig. 10 Results to the free text question "What are your personal thieves of time?" in winter semester $17 / 18$ - the answers are clustered in groups of similarity $(\mathrm{N}=57)$ 
Fig. 11 All submitted free text answers grouped into the presented categories

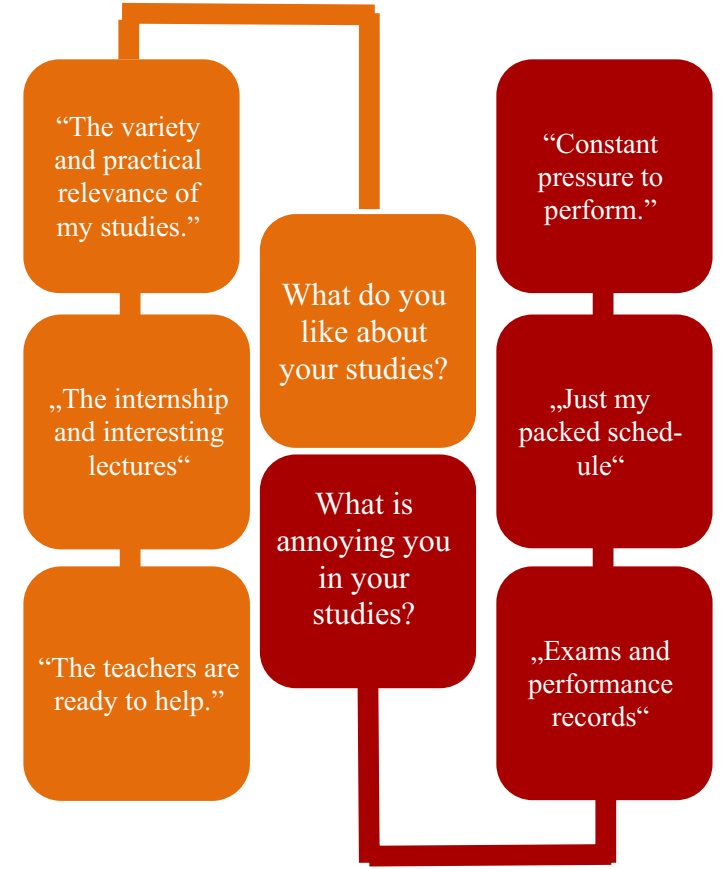

possibility to distribute information from the faculty and to get feedback from the students who are doing their legal clerkship throughout Germany.

Due to the university-wide rollout, the app reached a critical part of all students. The combination of free text (overall 670 submitted free text answers), multiple and single choice questions allows to address the micro and macro level and to get detailed insights. By counting the individual answers according to the free text questions "What do you like/ What annoys you about your studies?" and grouping them into categories shown in Fig. 11.

Which conclusions can be drawn about self-reflection processes in learning? Up to now, the app is giving first reflective impulses to freshmen. This happens especially related to professional knowledge, academic knowledge and self-regulating skills in a very practical way. Further developments have to deal with the entanglement of reflection processes and learning strategies. For this purpose, more work on self-reflection of the individual skills acquisition has to be done. That requires a clear conception of the levels of psychological processes taking place. To look at the use of metacognitive knowledge (Wright 1992) and other trainings of reflective skills (Gün 2011) could be a good starting point. Another important aspect could be the influence emotions have on reflective processes as well as feedback acceptance (Sargeant et al. 2008).

Subsequently, the prepared data on the reflective processes is made publicly accessible on a website for the students. ${ }^{20}$ Thus, users can gage themselves relative to the rest of their peers. Particularly at the end of the semester, Reflect.UP offers assistance by means of open questions, whereby the actual response to the application recedes into the background.

${ }^{20} \mathrm{https} / / /$ www.uni-potsdam.de/reflectup. 
Nonetheless, future efforts will aim to motivate the students to answer questions and most importantly to always give feedback when something is relevant to them. To achieve this, the "hotline", a permanently available possibility for feedback, should be promoted more. In addition, a future intention is to send urgent information affecting everyday university life (such as schedule changes) as push messages to the students.

\section{Summary and Outlook}

The article has shown how an ongoing mobile support offer for students in their introductory phase can be conceptualized, technologically developed and successfully implemented in the program structures. With Reflect.UP not only does the knowledge and skills expectation of the subjects become visible and comparable for the administration of study programs, but also students are sensitized by reflecting on their own skills acquisition. At the same time, a new communication channel evolves between students and university. The new insights into the actual beginning of studies achieved in this manner help to address individual problems and consider the structural conditions of starting studies from the student perspective.

Until now, the app is focused on the introductory phases across the subjects; mapping the course of a six-semester bachelor program in other fields is due to follow. Knowledge and competencies related to specific phases must be identified and transposed into questions that are to be expanded gradually, presenting in turn new challenges to the integrated competency framework.

Analogously, it is envisioned to extend the availability of the app for introductory phases at other universities, opening diverse possibilities for cooperation, testing, and comparison. From a technical point of view, universities should have the possibility to integrate the Reflect.UP app into their systems (e.g. authentication via the identity management system and customization of data privacy issues). It is intended to implement the demanded requirements already identified by the app. This involves implementing an audio record feedback (voice control) and the technical possibility to react directly to audio feedback from students. This would foster the level of commitment and increase the amount of interaction.

In total, these development steps make it possible to embed a much-needed offer for freshmen in a widespread manner, to further explore possibilities and limits, and to establish the app as an innovative instrument of situational data gathering. In the winter semester 2017/2018, the app was introduced at all faculties, which means that the app was published for all study programs at the University of Potsdam. The analysis of the concrete results and an evaluation of the implementation process itself, compared with the activities at our partner institutions, will be the subject of further publications. What are the next development steps and planned institutionalization stages? The presented competency framework will be both extended and specified. Thus, the reflective questions will be adapted to meet the specific requirements of the faculties and offered studies at best. It is also planned to integrate subject-specific sub-groups into the application. This is necessary to handle the total number of faculties, thus separating the user groups and providing subject-specific questions and inputs. Subsequently, it will allow to focus on the level of study programs and finally on single courses. Students generally evaluate Reflect.UP positively. From feedback messages, we have learned that they want to have more interactive content processed in the app. This could be hyperlinks to further information and additional learning 
materials. The functionality to be able to individually monitor reflection processes over time would be also beneficial. In the long run Reflect.UP could be extended by functionalities to socially compare the individual learning and competency achievement progress with others. This form of social alignment would also require enhanced communication and interaction possibilities.

The functionality of the application will be extended by a component, which offers an overview of all the user's submitted answers, the corresponding reflective question and the addressed competency aspects. Users will be able to see the so far addressed and not appealed competency aspects. Future research will evaluate whether this functionality will lead to higher level of self-reflection competency in the introductory phase. Therefore, two different versions of the app will be provided for users and will be distributed at random. A standardized survey will be used to measure self-reflection competency and compare it between the two groups.

Another interesting research question that can be addressed with this research design and a longitudinal survey is whether the self-reflection competency of freshmen changes over time. Do freshmen possess a higher or even lower self-reflection competency from year to year, or whether differences exist between students enrolled in different faculties? Future research will also focus on implications between emotions and self-reflection during phases of orientation (e.g. study entrance phase, job search after graduation). Combining the presented Reflect.UP and the FELX-App (Apelojg et al. 2018) will allow to get further insights on the role of emotions in the introductory phase.

Open Access This article is distributed under the terms of the Creative Commons Attribution 4.0 International License (http://creativecommons.org/licenses/by/4.0/), which permits unrestricted use, distribution, and reproduction in any medium, provided you give appropriate credit to the original author(s) and the source, provide a link to the Creative Commons license, and indicate if changes were made.

\section{References}

Altrichter, H., \& Posch, P. (2007). Lehrerinnen und Lehrer erforschen ihren Unterricht. Bad Heilbrunn: Klinkhardt.

Apelojg, B., Kiy, A., Lucke, U., Moebert, T. (2018) Emotionen: Stolpersteine, Krücken oder Antriebsmotor in der Hochschullehre? In Deimann, M. \& van Treeck, T. (Hrsg.), Digitalisierung der Hochschullehre (in publication). https://eric.ed.gov/?id=EJ738201.

Baumert, J., \& Kunter, M. (2006). Professionelle Kompetenz von Lehrkräften. Zeitschrift für Erziehungswissenschaften, 9, 469-520.

Bourdieu, P. (1977). Outline of a theory of practice. Cambridge: University Press.

Brodersen, F., Glaese, S., Lohse, L., Schadow, C., Steffen, H., \& Volpers, S. (2014). Aber scheiß drauf, O-Phase ist nur einmal im Jahr. Von Gemeinschaft und Geschlechtern, Wettbewerb und studentischen Kulturen in der Orientierungsphase. Göttingen: GOEDOC. https://nbn-resolving.de/ urn:nbn:de:gbv:7-webdoc-3942-7. Accessed 19 February 2019.

Dehne, J., Nguyen, T., \& Lucke, U. (2016). Bridging the institutional gap-Tracing lifelong skill evolvement. Amsterdam: The Higher Education Conference.

Fend, H. (2001). Qualität im Bildungswesen. Schulforschung zu Systembedingungen, Schulprofilen und Lehrerleistung. Weinheim/München: Juventa.

Foucault, M. (1993). Technologien des Selbst. In L. Martin, H. Gutmann, \& P. Hutton (Eds.), Technologien des Selbst (pp. 24-62). Frankfurt: Suhrkamp.

Giddens, A. (1979). Central problems in social theory: Action, structure and contradiction in social analysis. Berkeley: University of California Press.

Giddens, A. (1988). Die Konstitution der Gesellschaft. Grundzüge einer Theorie der Strukturierung. Frankfurt/New York: Campus. 
Gün, B. (2011). Quality self-reflection through reflection training. ELT Journal, 65, 126-135.

Heublein, U., Hutzsch, C., Schreiber, J., Sommer, D., \& Besuch, G. (2009). Ursachen des Studienabbruchs in Bachelor- und in herkömmlichen Studiengängen-Ergebnisse einer bundesweiten Befragung von Exmatrikulierten des Studienjahres 2007/08. Hannover: HIS - Forum Hochschule. https:// www.dzhw.eu/pdf/21/studienabbruch_ursachen.pdf. Accessed 19 February 2019.

Heublein, U., Richter, J., Schmelzer, R., \& Sommer, D. (2012). Die Entwicklung der Schwund- und Studienabbruchquoten an den deutschen Hochschulen-Statistische Berechnungen auf der Basis des Absolventenjahrgangs 2010. Hannover: HIS_Forum Hochschule. https://www.dzhw.eu/pdf/pub_ fh/fh-201203.pdf. Accessed 19 February 2019.

Hotchkiss, J. L., Moore, R. E., \& Pitts, M. M. (2006). Freshman learning communities, college performance, and retention. In Education economics (Vol. 14, no. 2, pp. 197-210). https://eric. ed.gov/?id=EJ738201.

Kiy, A., Geßner, H., Grünewald, F., \& Lucke, U. (2015). A hybrid and modular framework for mobile campus application. In J. Ziegler (Ed.), i-com, 14/1 (pp. 63-73). Berlin: De Gruyter.

KMK. (2014). Statistische Veröffentlichungen der Kultusministerkonferenz: Vorausberechnung der Studienanfängerzahlen 2014-2025 Erläuterung der Datenbasis und des Berechnungsverfahrens. https ://www.kmk.org/fileadmin/Dateien/pdf/Statistik/Dokumentationen/Dok_Vorausberechnung_2014. pdf. Accessed 19 February 2019.

Kossack, P., Lehman, U., \& Hauser, A. (2012). SEPHA - Ein Projektbericht: Befunde zur Gestaltung der Studieneingangsphase. In P. Kossack, U. Lehmann, \& J. Ludwig (Eds.), Die Studieneingangsphase - Analyse, Gestaltung und Entwicklung (pp. 17-30). Bielefeld: UVW UniversitätsVerlagWebler.

Kuckartz, U. (2012). Qualitative Inhaltsanalyse. Methoden, Praxis, Computerunterstützung. Weinheim/ Basel: BELTZ Juventa.

Lemke, T. (2000). Neoliberalismus, Staat und Selbstechnologien. Ein kritischer Überblick über die governmentality studies. Politische Vierteljahresschrift,1, 31-47.

Ludwig, J. (2012). Studieneingangsphasen als Professionalitätsproblem. In P. Kossack, U. Lehmann, \& J. Ludwig (Eds.), Die Studieneingangsphase-Analyse, Gestaltung und Entwicklung (pp. 45-56). Bielefeld: UVW UniversitätsVerlagWebler.

Orth, H. (1999). Schlüsselqualifikationen an deutschen Hochschulen. Konzepte, Standpunkte und Perspektiven. Neuwied/Kriftel/Berlin: Luchterhand.

Philipp, A., Dorlchter, J., Nanninga, J., Reimann, H., Ruck, A., Giemza, A., \& Hoppe, H. U. (2013). Meet2Learn Eine mobile Applikation zur Unterstützung von Lerngruppen. In A. Breiter, \& C. Rensing (Eds.), Proceedings of der 11. e-Learning Fachtagung Informatik (pp. 107-118). Bonn: Köllen.

Rensing, C., \& Tittel, S. (2013). Situiertes Mobiles Lernen-Potenziale, Herausforderungen und Beispiele. In C. De Witt, \& A. Sieber (Eds.), Mobile learning. Potentiale, Einsatzszenarien und Perspektiven des Lernens mit mobilen Endgeräten (pp.121-143). Wiesbaden: VS Verlag.

Sargeant, J., Mann, K., Sinclair, D., Van der Vleuten, C., \& Metsemakers, J. (2008). Understanding the influence of emotions and reflection upon multi-source feedback acceptance and use. Advances in Health Sciences Education,13, 275-288.

Schön, D. A. (1983). The reflective practitioner: How professionals think in action. New York: Basic Books.

Strauss, A., \& Corbin, J. (1996). Grounded theory: Grundlagen Qualitativer Sozialforschung. Weinheim: BeltzPVU.

Turner, V. (2005). Das Ritual. Struktur und Anti-Struktur. Frankfurt/New York: Campus Bibliothek.

Vossensteyn, H., Kottmann, A., Jongbloed, B., Kaiser, F., Cremonini, L., Stensaker, B., Hovdhaugen, E., \& Wollscheid, S. (2015). Dropout and completion in higher education in Europe: Main report. European Union. https://supporthere.org/sites/default/files/dropout-completion-he_en.pdf. Accessed 19 February 2019.

Wright, J. (1992). Reflections on reflection. Learning and Instruction, 2, 59-68.

Wyss, C. (2008). Zur Reflexionsfähigkeit und -praxis der Lehrperson. Bildungsforschung, 5(2). https:// www.pedocs.de/volltexte/2014/4599/pdf/bf_2008_2_Wyss_Reflexionsfaehigkeit.pdf. Accessed 19 February 2019.

Zender, R., Metzler, R., \& Lucke, U. (2013). FreshUP_A pervasive educational game for freshmen. Pervasive and Mobile Computing,14, 47-56.

Publisher's Note Springer Nature remains neutral with regard to jurisdictional claims in published maps and institutional affiliations. 